\title{
LA CONFORMACIÓN HISTÓRICA DEL MERCADO DE TRABAJO AGRÍCOLA EN EL VALLE DE MEXICALI
}

\author{
Por \\ José A. Moreno Mena*
}

\begin{abstract}
RESUMEN
En el presente trabajo, se pretende dar un breve bosquejo sobre algunos elementos que nos permitan entender el proceso de conformación del mercado laboral en el valle de Mexicali, desde su surgimiento hasta la actualidad. Para ello, se parte de reconstruir el proceso histórico que permitió sentar las bases materiales que posibilitaron la producción agrícola en escala ampliada y por ende, la reproducción de la fuerza de trabajo. Por último, se da una breve caracterización de la mano de obra que utilizó el capital extranjero durante los diferentes periodos.
\end{abstract}

\begin{abstract}
This article attempts to give a brief outline of the history of the labor market in the Mexicali Valley, from its beginning up to the present time. To accomplish this, it begins by recapitulating the historical process which laid the foundation for largescale agricultural production, and thus, generated a work force. Finally, there is given a brief description of labor which used foreign capital during each of the different periods.
\end{abstract}

\section{INTRODUCCIÓN}

El valle de Mexicali es una región agrícola, situada en el noroeste de la república mexicana, que colinda con el estado de California y una pequeña porción de Arizona. Tiene una extensión superficial de 273400 hectáreas aptas para el cultivo, de las cuales se siembran constantemente un poco menos de 200 000. Está bañado por las aguas del Río Colorado y tiene un clima extremoso, caluroso en verano y frío en invierno.

En su nacimiento, constituyó una unidad geográfica con el Valle Imperial del estado de California, delimitado actualmente por la línea divisoria entre México y Estados Unidos.

* Investigador del Instituto de Investigaciones Sociales de la Universidad Autónoma de Baja California. 
En toda la historia productiva del valle de Mexicali han estado presentes algunas constantes, como la inversión extranjera, la agricultura de riego, el acceso a la tecnologia y las relaciones asalariadas.

Durante más de seis décadas el mercado de trabajo local fue incapaz de cubrir la demanda de mano de obra en la región, por lo que se vio obligado a importar trabajadores foráneos. Así, la población migrante se constituyó como el pilar de la fuerza de trabajo en el valle de Mexicali, en buena parte de su corta historia.

En el presente trabajo se hace un breve recorrido histórico del valle de Mexicali, tratando de caracterizar a la mano de obra. Para ello se divide en varios periodos, en el primero, que abarca de fines del siglo XIX a 1937 , se analizan someramente las condiciones que permitieron el dominio del capital extranjero así como las situaciones que propiciaron la mexicanización de las tierras del valle mexicalense; el segundo, abarca de la reforma agraria hasta la crisis del algodón a finales de los años setenta y el tercero se refiere a las últimas dos décadas. Finalmente, se vierten algunas reflexiones finales.

\section{DEL SURGIMIENTO DEL VALLE DE MEXICALI A 1937}

En la segunda mitad del sigloxix se desarrollaron en nuestro país una serie de medidas emanadas de las leyes de Reforma, tendientes a colonizar las regiones más abandonadas del país. Estas medidas legislativas contemplaban las leyes de desamortización de los bienes eclesiásticos, que establecían la expropiacion de terrenos y bienes controlados por la iglesia y las comunidades indigenas; además, propiciaban la política de colonización de las tierras "vírgenes" por compañías deslindadoras extranjeras.

En esa misma tónica, para 1863, se promulga la Ley sobre enajenación de terrenos baldios, lo que permitió que grupos de empresas deslindadoras extranjeras se apropiaran de grandes extensiones de tierras en algunos estados del país.

Durante el gobierno de Porfirio Díaz, se abrieron las puertas al capital extranjero. En 1873 y 1894 se promulgaron algunas leyes de colonizacion, que otorgaban a las compañías deslindadoras hasta la tercera parte de los terrenos reclamados. Esta política pretendía estimular el establecimiento de centros de población en las regiones consideradas como despobladas. Pero también a nivel nacional, tenía una doble intensión, por una parte, crear una agricultura comercial destinada hacia la exportación, y por otra, satisfacer las necesidades del mercado interno.

Según Silva Herzog (1976:16-17), entre 1881-1896 se llegaron a deslindar cerca de 49 millones de hectáreas en el país, no todas obtenidas 
por ese método, sino por la apropiación violenta de las tierras en posesión de comunidades indígenas; esto permitió la liberación de una gran cantidad de mano de obra disponible para el capital.

En ese mismo tiempo, el capital internacional buscaba afanosamente incrustar sus intereses en los países del tercer mundo, es asf que se crean enclaves en varias regiones con potencial productivo, estableciéndose algunas plantaciones en Centroamérica, África, Asia, Sudamérica y en varios estados de la república mexicana.

Para los capitales norteamericanos, también en expansión, el suroeste de los Estados Unidos resultaba atractivo. Las tierras cercanas al Río Colorado fueron incorporadas al mercado para su venta y pronto las actividades economicas tuvieron un florecimiento inusitado.

En ese contex to, el valle de Mexicali y casi todos los terrenos considerados como baldíos, del entonces Territorio Norte de la Baja California, fueron concesionados a un grupo de compañías extranjeras de diferentes nacionalidades.

La localización privilegiada del valle mexicalense - vecino de los valles estadounidenses Imperial y Yuma- lo colocaban en una situación estratégica, por lo cual resultaba atractivo para la realización de inversiones.

\section{INICIO DE LA INVERSIÓN EXTRANJERA EN EL VALLE DE MEXICALI}

Al final del siglo XIX, el Territorio Norte de la Baja California se encontraba, casi en su totalidad, bajo el control de compañfas extranjeras. Un sinnúmero de concesiones se traspasaban a diferentes manos, hasta llegar al predominio de unas cuantas empresas, creándose latifundios.

Entre las más importantes, por su dominio territorial, encontramos a la llamada Compañía Inglesa y la Colorado River Land Company. ${ }^{2}$

En el proceso de apropiación de las tierras, un personaje mexicano tuvo una importancia primordial: Guillermo Andrade, quien en representacion de la Compañía Mexicana Agricola Industrial y Colonizadora de Terrenos del Colorado, celebró un contrato con el gobierno federal mediante el cual se le otorgaban 358235 ha. Uno de los puntos esenciales del mismo documento decía :

\footnotetext{
I Martha Stamatis sostiene que las caracteristicas que asume el desarrollo de la agricultura en el val le de Mexicali durante esa época, se asemeja a las que se desarrollaban en las llamadas economías de enclave, sobre todo a la variante de "agricultura de plantación" (VÉase Stamatis, 1987).

A partir de aqui, cuando nos refiramos a la Colorado River Land Company, lo haremos como La Colorado.
} 
...que el 8 de agosto de 1888 , se había ajustado un contrato con el C. Guillermo Andrade para la compra-venta de los terrenos nacionales compuestos de 358,235 Has.[...] de las cuales 305,735 estaban ubicadas en Baja Califomia y las restantes en Sonora (Soleno, 1972:29).

Posteriormente el mismo Andrade también adquirió los terrenos del rancho Los Algodones. En los contratos celebrados con el gobierno, se estipulaba que el dueño o concesionario no podría enajenar o hipotecar los terrenos a ningún gobierno extranjero, ni a individuos o empresas, sin el previo consentimiento del gobiemo mexicano. Pero Andrade, contraviniendo lo anterior, sirvio de puente para que las extensiones de tierra por él acumuladas, pasaran a manos de capital norteamericano.

A partir de 1899 se inicia el traspaso de sus propiedades y derechos a compañfas extranjeras, como la California Development Company (Estrella, 1981:82), también a inversionistas estadunidenses que posteriormente se unirian para formar la Colorado River Land Company.

En 1904 Andrade ya había vendido 292500 ha (Herrera, 1976:104) y los principales beneficiarios resultaron ser los socios de La Colorado.

En 1896, el norteamericano Charles Rockwood y su compañía Colorado River Irrigation se interesaron en conducir las aguas del Rfo Colorado hacia el Valle Imperial y después por consecuencia al valle de Mexicali. ${ }^{3}$ En un primer momento, pretendían encausar las aguas del Río Colorado hacia el estado de Sonora ; sin embargo, al no poder realizar su obra por razones técnicas y económicas, decide llevar a cabo un proyecto para irrigar al Valle Imperial y el delta del Río Colorado.

Tal empresa no le resultó fácil, puesto que se encontró con dos obstáculos importantes: en primer lugar, necesitaba un fuerte financiamiento; por otro lado, para conducir las aguas del Río Colorado hacia territorio mexicano, se necesitaba un permiso especial de las autoridades mexicanas, ya que no se podia otorgar ese tipo de concesiones a las compañías extranjeras establecidas en otro país.

Para resolver el primer impedimento Rockwood recurrió a la asociacion con George Chaffey, empresario estadunidense; para solucionar la

3 El Río Colorado, situado entre México y Estados Unidos bańa con sus aguas a los dos valles, que forman un delta. Su cuenca se extiende por los estados de Colorado, Wyoming. Utah, Nevada, Arizona, Nuevo México y California en los Estados Unidos. Desemboca en el golfo de California, atravesando una pequeña porción de territorio mexicano por los estados de Sosora y Baja California. En la república mexicana, el río recorre aproximadamente 160 kilómetros (Valenzuela, 1958:767-776).

4 Inicialmente Rockwood y su socio Jotton C. Bealty fundan la compañia Arizona and Sonora Land Irrigation Co., con el fin de realizar estudios para el riego de 600000 ha en el estado de Sonora. Posteriormente a esa compafifa le cambiaron el nombre y le pusieron Colorado River Irrigation Company. 
segunda dificultad, se asoció con Guillermo Andrade. De esta doble unión, surgió primero la compañfa California Development Company que se encargaría de proyectos de construcción de obras de riego y suministros de agua; después la Imperial Land Company que atenderfa la colonización de las tierras. Y como agente financiero se constituyó la Delta Investment Company.

Para llevar a cabo las obras y tener el permiso de las autoridades mexicanas, se creó una filial en México denominada Sociedad de Irrigación y Terrenos de la Baja California.

Las obras comenzaron en 1900 y el 14 de mayo de 1901, se derivaron las aguas del Río Colorado al canal del Álamo, llegando éstas a territorio norteamericano el 20 de junio del mismo año (Amaya y Ramos, 1977:12), comenzando así la irrigación de las tierras del Valle Imperial y posteriormente del valle de Mexicali.

Paralelamente a la irrigación de las tierras del delta del Colorado, se presentaban otras tendencias complementarias de la expansión de las empresas norteamericanas. Una se refería a las grandes inversiones que se estaban llevando a cabo en la región suroeste de los Estados Unidos (especificamente en la frontera con México) y la otra, a la construcción de comunicaciones ferroviarias que posibilitaran el abasto del mercado regional, tanto de productos como de fuerza de trabajo (Anguiano, 1991:16).

En el siglo XIX la península de Baja Califomia se encontraba prácticamente desconectada del resto del pars, únicamente existía la comunicación por la vía marítima y ocasionalmente por diligencias que se aventuraban a atravesar el desierto de Sonora. Resultaba más frecuente la relación comercial entre los escasos pobladores de Mexicali con las poblaciones del otro lado de la línea imaginaria que dividía a México de Estados Unidos.

A fines del siglo XIX, algunas compañfas capitalistas habfan adquirido terrenos agricolas y mineros en Baja California, Sonora y Sinaloa; y para el buen desempeño de sus trabajos, se requería la comunicación de esta región con el mercado norteamericano, destinatario principal de los productos obtenidos. Por tal motivo, se construyeron líneas ferrocarrileras en territorio mexicano para el tráfico y el tránsito de las mercancías.

En las regiones sur y occidental de la península, se construyeron algunas vías de comunicación ferroviarias, con el mismo fin y de ellas muy pocas se destinaban al servicio público. ${ }^{5}$

5 En 1883, la compañía europea de Luis Huller and Co., instaló algunas vas de ferrocarril en la ciudad de Ensenada y en 1891, la misma construye un tramo que va de San Quintín a San Simon, el cual tenía 10 kilómetros de largo (Anguiano, 1991:17). 
El ferrocarril que llegaría a la zona del Río Colorado se llamaba Southern Pacific, que iba desde Nueva Orleans hasta la ciudad de Los Ángeles, a través de Texas, el Río Grande y Gassdem por Chase (Anguiano, 1991:17). En 1877 sus redes se habían extendido hasta Yuma, Arizona. Este tramo que comunicaba a la capital de Arizona con Los Ángeles pasaba por territorio del Valle Imperial. Más tarde, se construyó otra rama que enlazaba Yuma y San Diego, misma que pasaba por los poblados de Los Algodones y Mexicali, en territorio mexicano.

Esta red de comunicaciones ferroviarias permitio al valle de Mexicali conectarse al resto de la península y al estado de California. También contribuy 6 a traer capitales para el desarrollo de las actividades productivas y al mismo tiempo, incremento el movimiento de mercancías, fuerza de trabajo y capitales hacia esta región y fuera de ella ${ }^{6}$ (Anguiano, 1991:19).

\section{EL DOMINIO DE LA COLORADO RIVER LAND COMPANY EN EL VALLE DE MEXICALI}

Ya instalada en el valle de Mexicali, La Colorado desarrollo una campaña de compras con el propósito de apoderarse de todos los terrenos que tenfan otras compañfas. Finalmente, llego a poseer la cantidad de $325492 \mathrm{ha}$, es decir, casi todo el valle mexicalense.

Ya habiéndose apropiado de las tierras, se presentaba la imperiosa necesidad de asegurar el suministro y control del agua. Para ello, La Colorado inició los pasos necesarios; compró las acciones de la compañía Sociedad de Irrigación y Terrenos de la Baja California, con toda la tierra que Guillermo Andrade habia otorgado como aportación en la constitución de dicha companía, así como los derechos del agua, por lo que de esta manera La Colorado aseguraba cuando menos el control de una gran cantidad de tierras irrigables.

La empresa que dominada la mayor parte del agua del valle se denominaba Compañfa de Terrenos y Aguas de Baja California, cuyos socios fundadores llevaban una relación muy estrecha con los miembros de La Colorado, de tal forma que estos últimos ejercían también un control

\footnotetext{
6 Al valle de Mexicali acudieron trabajadores provenientes de las minas del sur de la peaínsula, con el proposito de laborar en las construcciones de las vías del ferrocarril; también arribaron otros por territorio norteamericano, principalmente de origen asiático (Anguiano, 1991:17).

La Sociedad de Irrigación y Terrenos de la Baja California había tenido un estrepitoso fracaso económico en 1905 al provocar una inundación que afectó, tanto al Valle Imperial, como a la incipiente ciudad de Mexicali, por esa razón, los antiguos socios se vieron obligados a vender sus acciones a La Colorado.
} 
indirecto del agua. Además, para poder llevar a cabo cualquier obra que involucrara terrenos dominados por La Colorado, había que pedirle permiso o rentarle a la propia compañfa latifundista la proporción que se fuera a utilizar.

Así, se presentó que La Colorado River Land Company tenía directa e indirectamente el control de los principales medios de producción del valle mexicalense.

Con el control de la tierra y el agua, los accionistas de La Colorado se encontraron con la urgente necesidad de crear una infraestructura de riego que posibilitara la ampliación de más tierras al cultivo, lo que implicaba realizar una fuerte inversión de capital. Para lograr lo anterior, según afirma Grijalva (1983:356), la compañía desembolsó la suma de 12000 dólares en la construcción de canales, diques, caminos, carreteras y nivelación de tierras.

Inicialmente, la actividad ganadera era la que más atención recibía, aprovechando que las tierras recientemente adquiridas se encontraban cubiertas por diferentes forrajes aptos para el ganado. También se daba impulso a la explotación del cáñamo silvestre, que existía en abundancia en toda la region. Posteriormente, comenzo a cultivarse algodon, maf́, cebada y trigo para consumo local.

Los socios de La Colorado tenían conocimiento de las amplias perspectivas agrícolas que ofrecían estas tierras, sobre todo, porque se contaba con agua suficiente para poder regarlas. Había que transformar esa porción de territorio ocioso y convertir al valle de Mexicali en un emporio agricola, destinado a la producción de cultivos que tuvieran una fuerte demanda internacional, cuyo fin último sería la exportación.

Para lograr lo anterior, La Colorado arrendo la tierra a pequeñas compañfas o empresas familiares de capital norteamericano, chino, indio, etcétera, con las cuales compartieron la fuerte inversión. Fueron propiamente ellas las que abrieron y limpiaron las tierras para el cultivo; además las obras de irrigación también quedaron bajo su responsabilidad.

Por si fuera poco La Colorado se reservó el derecho de poder utilizar las tierras, aún y cuando estuvieran arrendadas. De esta forma, la compañía garantizaba por un lado, sus ganancias por concepto de renta y al mismo tiempo la ampliación de más tierras para el cultivo, a tal grado que si la empresa arrendataria se iba o terminaba el contrato, la compañía se quedaba con toda la infraestructura.

Estas pequeñas empresas arrendatarias, a su vez, las subarrendaban a particulares, creando así una cadena en donde los últimos, es decir, los subarrendadores, eran los que llevaban el mayor peso de la explotación directa de la tierra. 
La comprobada fertilidad de los suelos del valle de Mexicali y el agua disponible del Río Colorado, así como las condiciones climáticas adecuadas, centraron la atención de la companfía extranjera sobre un producto que tenía una gran demanda comercial en el exterior, el algodón.

$\mathrm{L} O s$ socios de $\mathrm{La}$ Colorado viendo las amplias perspectivas que ofrecía la fibra, deciden incursionar en el negocio y a partir de la primera década del siglo XX, comenzó a generalizarse su siembra en todo el valle.

En los años posteriores, el algodón adquirió una extraordinaria importancia, a tal grado que se convirtió en el principal cultivo del valle mexicalense. Pero eso no hubiera sido posible sin la conjunción de varios elementos que permitieron su desarrollo, como la existencia de una infraestructura de riego, las industrias de procesamiento, el financiamiento, la fuerza de trabajo y la utilización de herramientas de trabajo modernas.

En lo que respecta a esto último, es un hecho que desde el surgimiento del valle de Mexicali como empresa agricola, se tuvo acceso en forma inmediata a medios de trabajo modernos, en esto La Colorado también tuvo ingerencia al introducir tractores, cultivadoras, sembradoras, etcétera, en los campos de cultivo (Anguiano y Moreno, 1988). Esto permitió el desarrollo de una agricultura mecanizada cuando menos en las primeras fases del proceso productivo. Sin embargo, no podía prescindir del uso de la mano de obra, sobre todo en periodos de cosecha.

La tecnología de punta que se utilizaba en el vecino Valle Imperial influyó para que esta situación se presentara.

Con estos elementos, los arrendatarios y $\mathrm{La}$ Colorado pudieron desarrollar una agricultura moderna, que curiosamente tenía los rasgos esenciales de las plantaciones de fines del siglo XIX (Stamatis, 1987).

Para completar el cuadro de dominio, los socios de La Colorado, amparándose en el argumento de que buscaban beneficiar a sus arrendatarios y dando a conocer las "bondades" que les traeria a los productores locales despepitar el algodón en tierras mexicanas, decide instalar en 1922 una empresa despepitadora, que por su magnitud llego a ser la más grande del mundo. A ésta se le denominó Lower Colorado Gining Co. S.A. (De Vivanco, 1924:391).

Así la empresa extranjera no sólo se jactó de poseer el "Rancho algodonero más grande del mundo" sino también tener la mayor despepitadora.

Por si fuera poco, La Colorado también les "ayudaría" a vender la fibra a los precios del mercado mundial. Para esto, la compañía instaló dentro de sus oficinas un departamento destinado a las ventas, donde se les comunicaba a los agricultores los precios vigentes en los principales mercados del mundo. 
Por otra parte, con el fin de realizar procesamientos y transformación del producto, se instala la Compañía Industrial Jabonera del Pacifico en 1925 , con capital también de La Colorado, donde los miembros del consejo de administración eran prominentes socios de la compañía extranjera. En su edificio operaba el Banco Agricola Refaccionador, que otorgaba créditos por medio de "fianza prendaria" sobre las cosechas de los propios agricultores, estableciendo así un control sobre la producción de los arrendatarios. De esta forma, se observa cómo la Colorado River Land Company no sólo ejerció un control de los principales medios de producción en el valle de Mexicali, sino que también logro dominar todas las etapas del proceso productivo del algodón, desde la producción, procesamiento y comercialización hasta el financiamiento, convirtiendo al valle en un basto enclave agrícola.

\section{LA PARTICIPACIÓN DE LA COLORADO RIVER LAND COM- PANY EN LA CONFORMACIÓN DEL MERCADO DE TRABAJO}

Para llevar a cabo la explotación de las tierras del valle de Mexicali, el capital extranjero tuvo que crear las premisas de su propio desarrollo, como lo afirma correctamente Anguiano (1987:16). Para ello, enfrento un sinnúmero de problemas entre los cuales, el más importante lo constituy6 sin duda, la inexistencia de un mercado de trabajo local previamente conformado y suficiente, que permitiera la explotación de las hectáreas abiertas al cultivo; recordemos que para ese entonces la población de la región era sumamente escasa.

Con la llegada de la irrigación y la construcción de las vías ferroviarias en la región, se marcó la posibilidad de un importante desarrollo agrícola y al mismo tiempo se creó una demanda de fuerza de trabajo, misma que no podía ser satisfecha por el incipiente mercado laboral regional.

Las crecientes actividades productivas en ambos lados de la frontera, pronto demandaron cantidades importantes de trabajadores estacionales y permanentes, mismas que tenfan que ser satisfechas con mano de obra migrante procedente de otras regiones. Las empresas capitalistas jugaron un papel proponderante en la introducción de esa fuerza de trabajo.

En ese tiempo, la situación de la mano de obra se encontraba de la siguiente manera:

\section{Mano de obra local}

La población mestiza de origen mexicano asentada en la localidad era sumamente escasa, la mayoría provenfan de las migraciones del sur de la 
península, principalmente de los pueblos mineros, otros del estado de Sonora; mientras que los menos, habían llegado de los Estados Unidos. Según Aguirre Bernal, para 1906 había en Mexicali sólo 550 habitantes mestizos (Aguirre, 1990:33).

En lo que respecta a la mano de obra indígena, en la región se tienen antecedentes de que en el extremo norte de la penf́nsula de Baja California existieron durante siglos tribus de indigenas seminómadas denominadas: diegueños, yumas y cucapá, quienes practicaban una economía de autosubsistencia. ${ }^{8}$ En el siglo xvm tuvieron contacto con los misioneros franciscanos y dominicos, algunos grupos fueron sometidos, mediante el convencimiento o la violencia, a vivir bajo otras reglas que no eran las de sus ancestros, pero ese proceso se trunco al concluir la etapa misional. Pasaron años sin tener, nuevamente, contacto con otras poblaciones españolas o mestizas.

Durante la segunda mitad del siglo XIX, algunas compañfas norteamericanas de navegación tuvieron contacto con las tribus cucapá y yumas; a las cuales comenzaron a emplear como abastecedores de leña para los pequeños barcos de vapor.

Ya en las postrimerías del siglo XIX, los cucapá fueron empleados como asalariados en el tendido de las vías del ferrocarril Southem Pacific y como vaqueros en los ranchos de Yuma, Arizona.

Sin embargo, el número de indigenas que se incorporaban a estas labores resultaba muy reducido. La mayoría seguían con sus actividades rutinarias o bien, emigraban hacia otras regiones.

La entrada de la irrigación en gran escala y la consecuente transformación de las tierras ociosas en un gran latifundio productivo, marcaron el principio de una fase de absorción de las familias cucapá y su paulatina inserción en los procesos productivos capitalistas. Esto, sin duda trajo un cambio cualitativo y cuantitativo en las relaciones que habían mantenido estas tribus con grupos de norteamericanos y mexicanos hasta fines del siglo xIX (Gómez, 1983:11).

En las comunidades indigenas no se presentó un proceso de proletarización inmediata, sino que fue paulatino y se generaliz 6 con la entrada de La Colorado, pues el capital extranjero comenzo a producir y a comercializar en gran escala productos agrícolas. Las compañías limitaron el territorio en el que los indigenas se movían libremente y los obligaron a emigrar. En ese sentido, fueron despojados de sus tierrras.

8 Se tiene evidencia de que estos grupos llegaron a practicar una agricultura incipiente. La existencia de pequefios y rudimentarios sistemas de diques que pretendlan tener cierto control de las crecientes del Rfo Colorado, son una prueba de ello. 
Al parecer los grupos no opusieron resistencia a la entrada de las compañfas, cuando menos no existen referencias sobre esto. Algunos indígenas - los menos - fueron integrándose como asalariados a los procesos productivos de la naciente agricultura comercial; otros emigraron hacia las zonas montañosas y crearon asentamientos; mientras que un tercer grupo decidió buscar nuevas tierras donde asentarse.?

\section{La mano de obra de origen asiático}

Debido a la escasez de trabajadores radicados en la localidad, el capital extranjero busco alternativas para contar con suficiente mano de obra, encontrándolas en la importación de trabajadores de origen oriental, principalmente chinos.

Algunas empresas norteamericanas ya tenían la experiencia de haber contratado trabajadores "chinos" en varias estidades de Estados Unidos, por lo que conocfan las "ventajas" de contar con los servicios de este tipo de trabajadores que no protestaban por las condiciones laborales infrahumanas, ni por el ritmo de trabajo; tampoco por los bajos salarios. Era pues, el trabajador ideal para una empresa capitalista en expansión, que pretendfa maximizar sus ganancias invirtiendo lo menos posible, en un emporio agrícola no explotado aún.

Al respecto, resulta ilustrativo el comentario del cónsul norteamericano Boyle, asentado en la ciudad de Mexicali, quien describe a esta mano de obra como "trabajadores duros, productores de riqueza, dociles y sujetos a la explotación" (Hude-Hart, 1986:12).

Por otro lado, además de los salarios infimos que pagarian a estos trabajadores, al mismo tiempo La Colorado se protegeria de una posible reclamación territorial a futuro, en el caso de haber utilizado únicamente trabajadores mexicanos.

Los socios de La Colorado tuvieron una participación destacada en la introducción de trabajadores asiáticos, no sólo se concretaron a sugerir a sus arrendatarios que contrataran mano de obra extranjera, sino que intervinieron de una manera directa (Grijalva, 1983). También tenía gran influencia en las determinaciones de orden político del gobierno local,

\footnotetext{
9 La incorporación de los indígenas a la economía capitalista como trabajadores asalariados, planté́ un desequilibrio en la relación con el medio, manifestíndose en una serie de movimientos que dispersaron a las tribus y ocasionaron finalmente la pórdida de su territorio. Algunos se trasladaron hacia la ciudad de Mexicali, otros se dispersaron a través de la frontera de Baja California; otros más se mudaron a Arizona, en los alrededores de Somerton y al sur de San Luis Río Colorado, Sonora.
} 
Hude-Hart nos comenta un suceso que aconteció en 1913, en donde se refleja todo lo anterior:

En julio de 1913 un caso muy interesante demandado por Chandler, en contra de la oficina de Inmigración de Mexicali, la cual rechazaba admitir más chinos de Hong Kong. Si esto se llevaba a cabo, sería la ruina para el cultivo del algodón y por ende, para la economía de la península. El subinspector de Inmigración explicó la razón, basándose en el terreno de la salud y alegando que a 500 chinos admitidos anteriormente, los tenían en seis bungalow o subterráneos para fumar opio, estos mismos estaban enfermos y no trabajaban; y sus vecinos se encontraban muy molestos por ello.

Chandler y su Colorado River Land Co, aplicaron suficiente presión al gobernador del Territorio Norte de la Baja California, para que ordenara al subinspector que permitiera la entrada de todos los trabajadores chinos contratados por la compañía, con un examen físico. La compañía aceptaría los gastos de los exámenes médicos. (1986:12).

En este comentario se observa no sólo la participación directa de la compañía transnacional en la importación de trabajadores de origen oriental, sino también, la importancia que tenía esta mano de obra para el desarrollo de la agricultura en el valle de Mexicali. Además se ve que éste, durante las primeras décadas, estuvo basado principalmente en la superexplotación de la mano de obra china. Las condiciones a que estaban sujetos los jomaleros orientales eran deprimentes, salarios muy bajos, no existía día de descanso, con horarios extenuantes bajo un intenso calor, los médicos escaseaban por lo que resultaba frecuente la muerte por insolacion, ${ }^{10}$ las habitaciones en que residían por lo regular eran de cachanilla, mezquite, madera o de adobe (Auyón, 1991:42).

La mayoria de esta mano de obra provenía de las provincias chinas de Canton y Hong Kong, pero también llegaban inmigrantes radicados temporalmente en California, EUA y de algunos estados de la república mexicana. Su origen era eminentemente rural; casi todos de sexo masculino; constituía una mano de obra joven y no sabían hablar el idioma español.

Durante el periodo que La Colorado utilizo gran cantidad de fuerza de trabajo de origen oriental, contó con el apoyo velado del gobierno local.

La Inmigración de estos asalariados se venfa dando desde 1905, sin embargo, es hasta la llegada del coronel Esteban Cantú al gobierno del

${ }^{10}$ Un pionero chino que trabajó en esas épocas afirma que "en el verano se moría un chino por cada 10 hectíreas de cultivo, debido a las inclemencias del tiempo y por el trabajo pesado" (Ver Auyón, 1991). 
Territorio Norte de la Baja California, en 1914, cuando adquiere magnitudes extraordinarias. Este gobernante, no s6́lo legalizo la entrada de trabajadores chinos, sino que también la propició y se aprovechó de ella (Aguirre, 1983:174).

En esos años, Cantú había estado gobernando el territorio casi al margen de la federación, mantenía una semindependencia con respecto al gobierno federal, por lo que constantemente enfrentaba un sinnúmero de problemas con las facciones que se disputaban la dirigencia del país. Por esa razón, se vio obligado a crear su propia base economica, que le permitiera solventar los gastos de las acciones que emprendieran sus funcionarios; $y$ una de las formas de allegarse fondos era cobrando cuotas por cada individuo que se internara al territorio.

Conociendo de antemano la gran demanda de fuerza de trabajo que tenian las empresas extranjeras y los arrendatarios del valle de Mexicali, el gobernante no puso obstáculos administrativos en el ingreso masivo de este tipo de trabajadores. De esta manera aseguraba la estabilidad del erario público y podia llevar una relación cordial con las empresas extranjeras que controlaban el capital y la economía local.

Así, como resultado de esta política, para 1918 ya había más de 5000 chinos laborando en el valle de Mexicali, en forma permanente. Para 1926, la cifra oficial era de 5795 personas de origen chino, 1066 japonés y 101 de la India (Rodríguez, 1927:178). ${ }^{11}$

Los inmigrantes chinos no desarrollaron únicamente actividades de asalariados, algunos se convirtieron en arrendatarios de la propia compañfa, fungiendo como supervisores de sus propios paisanos.

Con la llegaba de los chinos se pretendía conformar un mercado laboral estable, con fuerza de trabajo extranjera, docil y fácil de explotar, acorde con los requerimientos de la producción de las empresas agrícolas transnacionales.

\section{La mano de obra migrante de origen mexicana}

Por su carácter fronterizo, el valle de Mexicali era utilizado como una zona de paso hacia el vecino y rico Valle Imperial, en California. En ese sentido, la mano de obra migrante mexicana era compartida por ambos valles, en donde este último, por presentar mejores condiciones laborales y salarios más atractivos, resultaba favorecido.

\footnotetext{
1 Aunque las fuentes oficiales nos dicen que habia 5000 pobladores de origen chino, otros autores mencionan que su número llegaba a 8000 y hasta 12000 . (Ver Samaniego, 1991).
} 
Durante las primeras décadas del siglo $\mathrm{XX}$, la población mexicana asentada en la region comenzo a incrementarse con grupos de individuos atraídos por las perspectivas laborales que ofrecía el inicio de las obras de riego y la apertura de las tierras del valle de Mexicali. Pero los mexicanos estaban excluidos de todo proyecto de desarrollo económico agrícola, implementado por la compañía extranjera que detentaba el control de las tierras. No se les admitía como arrendatarios, pero sí como fuerza de trabajo, con algunas desventajas respecto a la mano de obra china. Su número resultaba sumamente inferior respecto a los orientales; además, sus labores se destinaban principalmente a actividades no agrícolas, como la construcción de las vías de los ferrocarriles.

Aunque ya se tenían antecedentes de la incorporación de mano de obra de origen mexicano al valle de Mexicali, no es sino hasta el lapso que va de 1916 a 1918 cuando su integración se da masivamente en las empresas agrícolas. Esto fue así porque el mercado laboral local seguía siendo incapaz de cubrir la demanda de mano de obra, por la constante expansión de las tierras de cultivo; además, durante esos años el gobierno local adoptó una política restrictiva para la inmigración de más trabajadores chinos.

Para ese entonces, ya existían las comunicaciones - aunque incipientes- de la península con el resto del pafs por medio de los ferrocarriles que llegaban por la ciudad de Nogales y las pocas carreteras que conectaban Baja California con el estado de Sonora.

A partir de 1919, y durante los siguientes cinco afíos, la Cámara Nacional de Agricultura del Distrito Norte (que agrupaba a los productores locales de algodón), implementó la práctica de traer anualmente, mediante enganchadores profesionales, hasta 24000 trabajadores mexicanos para las labores del campo, prometiéndoles trabajo durante todo el año. Esto ocasiono que se presentara una corriente de inmigración importante de los estados de Sonora, Sinaloa y el Distrito Sur de la península (De vivanco, 1924:187).

Aunque se hacían esfuerzos para contar con una fuerza de trabajo estable, éstos resultaban frustrados por la incesante competencia con el Valle Imperial y las características del trabajo estacional del cultivo algodonero. Al respecto, en la obra de Aurelio de Vivanco escrita en los años veinte, se menciona que:

...hasta el año de 1924, se estuvo observando la práctica de traer braceros de los estados de Sonora y Sinaloa, con destino expreso a la pizca del algodón. El gobiemo advirtió los serios inconvenientes que presentaba esa práctica, encontrando como principales los siguientes:

a) la mayoria de los braceros no regresaban a sus respectivos puntos 
de partida, b) alentados por la bondad de los salarios percibidos durante la época de recolección, muchos obreros determinan radicarse definitivamente en el distrito $\mathrm{y}$ al terminar la cosecha, de manera automática se encuentran frente a una situación comprometida, debido a la falta absoluta de trabajo y la carencia de recursos pecunarios para afrontar y salvar la crisis, acentuando, por ende, el desequilibrio entre la oferta y la demanda de braceros, no obstante que los trabajadores que tienen varios afios de residencia en el distrito preven la época inactiva y saben salir avantes de ella, y c) ante la falta de trabajo y atraídos por la pujanza económica del vecino estado de California, era frecuente el caso de que nuestros braceros emprendieran la cmigración a los Estados Unidos, restando así muchos y vigorosos brazos a la república y contribuyendo directamente al descenso fatal del volumen de nuestras exportaciones agricolas e industriales... (De Vivanco, 1924:359).

Las condiciones de vida de los trabajadores agrícolas mexicanos no distaba mucho de las de sus compañeros chinos, si bien es cierto que obtenfan salarios que podían considerarse como altos, entre 5 y 12 pesos diarios (Samaniego, 1991:284) su situación de migrantes los ponfa en igualdad de condiciones a los otros trabajadores, puesto que se velan obligados a realizar sus compras en el vecino poblado de Caléxico; además no recibían esas remuneraciones todo el año dadas las caracteristicas de su trabajo temporal.

La mano de obra mexicana enganchada también era sumamente joven y de origen rural, con un nivel educativo bajo.

Es así que durante este periodo se va conformando un mercado laboral, con fuerza de trabajo migrante de origen oriental, y como complemento de ella, los pocos indígenas locales y los migrantes mexicanos, que venían o eran enganchados temporalmente para las pizcas.

\section{EL PAPEL DE LOS JORNALEROS AGRÍCOLAS EN LA MEXI- CANIZACIÓN DE LAS TIERRAS DEL VALLE DE MEXICALI}

En el transcurso del tiempo, se conjugaron una serie de factores endógenos y exógenos que fueron poco a poco posibilitando el poblamiento del valle de Mexicali; entre ellos se pueden mencionar, la construcción de las vías del ferrocarril, que permitieron el abasto de fuerza de trabajo hacia la región; el auge algodonero, debido a la demanda mundial que permitió ampliar las fronteras agrícolas; la primera guerra mundial; la ley seca que prohibía la venta de bebidas embriagantes en Estadas Unidos, por lo que sus nacionales se desplazaban a las ciudades mexicanas fronterizas incrementando las oportunidades de empleo; la crisis del 29 , que trajo una 
oleada de trabajadores mexicanos indocumentados devueltos hacia México y la Reforma Agraria del país, que luego del reparto de tierras, una gran cantidad de campesinos quedo sin ella y emigraron hacia la frontera norte.

También algunas acciones gubernamentales locales contribuyeron a la creación de asentamientos humanos, como las medidas adoptadas por Esteban Cantú de expropiarle algunos terrenos a las compañías extranjeras; las reglamentaciones al trabajo que implementó Abelardo L. Rodríguez en la segunda mitad de la década de los veinte mediante las que obligaba a los negocios a utilizar el $50 \%$ de trabajadores mexicanos.

Resulta significativo el año de 1921, porque en esa fecha se presento una repatriación importante de mexicanos que laboraban en Estados Unidos. El valle de mexicali fue receptor de una gran parte de esa mano de obra que se quedo sin trabajo, pronto se comenzaron a manifestar movimientos de jornaleros que exigían empleo y mejores condiciones laborales como la Unión de Obreros Libertarios de influencia anarco-sindicalista, afiliada a la Confederación General de Trabajadores, esta agrupación de jornaleros realizó algunas huelgas en 1921 (Samaniego, 1991:295).

La crisis del 29 fue uno de los acontecimientos que más influyó en el crecimiento demografico en Mexicali. En efecto, la recesión en Estados Unidos trajo miles de repatriados mexicanos que llegaron a la ciudad de Mexicali provenientes, principalmente, de Arizona y California, con la intencion de establecerse temporalmente en la región. Lo anterior, creo una concentración de población sin precedentes, ante la cual la capacidad del gobierno para otorgarles acomodo resultó insuficiente; además, la compañía extranjera se opuso rotundamente a que se asentaran en "sus tierras".

Este hecho Herrera Carrillo lo relata de la siguiente forma:

Los contingentes bumanos arrojados hacia Mexicali por la resaca de oleadas de braceros que no encontraban acomodo en los terrenos de "La Colorado", contribuirían en gran parte al crescendo de la ciudad y recargaban de atmósferas su fuerza expansionista y su presión contra la misma compañía que los arrojaba de su latifundio tan luego como dejaba de necesitarlos (Herrera, 1976:118).

Estos acontecimientos trajeron una migración importante que propicio un crecimiento poblacional extraordinario (ver Lapman, 1975). Al mismo tiempo, permitieron ir conformando un mercado laboral local (aunque todavfa inestable) suficiente para levantar las cosechas del valle de Mexicali durante este periodo. 
Muchos trabajadores repatriados logran establecerse en algunos asentamientos, los cuales son apoyados inmediatamente por el gobierno del territorio. Pronto surgen grupos de solicitantes de tierras que ven la posibilidad no muy remota de obtener una parcela para trabajarla.

Los mexicanos recién llegados tenían necesidad de trabajo y vivienda, para lo cual, exigian al gobierno local la nacionalización de las propiedades en manos extranjeras.

Las demandas se transformaron en movimientos sociales que reivindicaban la tierra. Y de las peticiones se pasaron a las acciones, desarrollándose algunas invasiones en las propiedades que controlaban las compañías norteamericanas. Una de las más importantes fue la que llevaron a cabo trabajadores agricolas deportados de Estados Unidos comandados por el ex coronel villista Marcelino Magaña. Quienes invadieron las tierras del italiano Víctor Carusso en 1922. Años más tarde, los jornaleros agricolas de la Colonia Gómez y la Álamo Mocho se organizan en el Sindicato de Obreros y Campesinos para defender los derechos de los trabajadores del campo y establecer una junta de Cociliación y Arbitraje, asf como la fijación de un salario mínimo (Aguirre, 1966:312). Dentro de los fines del sindicato, también se incluyo la demanda por la tierra.

Posteriormente, en 1930, un grupo de jornaleros agrícolas agrupados en la Confederación General de Trabajadores del Valle de Mexicali, donde participaba una mujer llamada Felipa Velázquez, desarrollan un movimiento con gran difusión nacional que marcaba el preludio del ocaso de la compañía extranjera. Ya para ese año, la población mexicana residente en el valle de Mexicali era proporcionalmente mayor que la oriental.

Durante todo ese periodo se presenta el auge de las organizaciones sindicales en el medio rural. De 1932 a 1937 se registraron 34 sindicatos, de los cuales 14 obtuvieron contratos colectivos con las empresas que laboraban (Figueroa, 1992). Pero la permanencia de esas organizaciones obreras resultaba effmera, puesto que pronto cambiaban las demandas laborales por las campesinas. La demanda por la tierra, se convirtio en el eje principal de sus luchas.

Posteriomente, algunos grupos se organizaron en una federacion campesina integrada a la recién formada CNC (Confederación Nacional Campesina) y comienzan a demandar tierras.

Todos esos movimientos tuvieron su conclusión en 1937 cuando se llev6 a cabo El Asalto a las Tierras, que dio inicio a la Reforma Agraria en el estado. Precisamente esa etapa coincidió con una política favorable hacia el sector agricola nacional, en donde las reformas cardenistas, habfan traído una extensa repartición de tierras, favoreciendo a un gran número de campesinos. En todos estos movimientos que llevaron a la recuperación 
de las tierras para los nacionales, la participación de los jomaleros agricolas migrantes fue determinante.

\section{DELA REFORMA AGRARIA HASTA LA CRISIS DEL ALGODÓN}

A partir de la Reforma Agraria en el valle de Mexicali, se transformó la tenencia de la tierra y un gran número de jornaleros agricolas se convirtieron en noveles campesinos. El sistema ejidal asumio un papel preponderante. Los arrendatarios y trabajadores chinos fueron abandonando paulatinamente el campo para instalarse en la ciudad o bien emigrar hacia otros paises.

El estado mexicano dio un fuerte apoyo en infraestructura y créditos, por lo que la producción crecio extraordinariamente. Para ese entonces, la política agraria nacional había dado un giro radical, al priorizar las inversiones públicas hacia la sustitución de importaciones y la irrigación a gran escala. Los Distritos de Riego del norte y noroeste fueron de los más favorecidos por esa política. En Mexicali se creó el Distrito de Riego en 1939, para favorecer a los nuevos campesinos.

La economfa campesina en el pais sufrio los estragos de esta nueva visión del desarrollo y el éxodo rural se incrementó notablemente.

El capital extranjero no abandonó el valle de Mexicali, sino que busco otras formas de participación, como el otorgamiento de créditos a cambio de las cosechas, de esta forma se presenta un auge de las compañías refaccionadoras, que abarco el periodo de los años cuarenta hasta finales de los cincuenta, en que La Jabonera, principal empresa refaccionadora extranjera concluyó sus actividades en la localidad (Sánchez, 1990).

\section{Los "booms" algodoneros}

En el periodo 1939-1945 se presenta un gran auge del cultivo del algodón en la región. Con el advenimiento de la segunda guerra mundial, la demanda internacional de la fibra creció notablemente y el valle de Mexicali adquirió un papel importante a nivel nacional. Las hectáreas sembradas se incrementaron de 40000 en el ciclo 1939-1940 a 89458 hectáreas en el ciclo 1943-1944 (ver cuadro 1). Lo anterior propició una fuerte demanda de mano de obra, que solamente podia ser cubierta por trabajadores migratorios.

Para 1949 y hasta 1960, nuevamente se presenta un "boom" del cultivo algodonero, en este caso fueron varios los factores que se conjugaron, entre ellos la devaluación de la moneda mexicana frente al dolar en 1949, la guerra de Corea y otra devaluación en 1953. 
Esta etapa se considera de "bonanza" para los agricultores del valle de Mexicali, porque los precios del producto se cotizaron muy altos y las ganancias fueron buenas. Se llego a rebasar la cantidad de las 100000 hectáreas sembradas, manteniéndose constante durante varios ańos ${ }^{12}$ (cuadro 1).

Esa situación influy6 de manera importante en el incremento del empleo, a tal grado que para esos ańos la actividad algodonera daba trabajo a 4000 obreros de planta en las industrias de procesamiento y a 30000 pizcadores temporales (Fuentes, 1990:47).

\section{La migración de mano de obra hacia la frontera}

El proceso de migración de la fuerza de trabajo hacia la frontera siguió su paso inexorable. Cuando se inauguro el tramo del ferrocarril PascualitosPuerto Peñasco, la comunicación con el resto de la república se hizo más fácil para el estado de Baja California.

La transformación que venfa sufriendo la economfa del país en general, donde la política de sustitución de importaciones, que estaba causando graves estragos en la economía campesina y obligaba al campe-sino a salir a vender su fuerza de trabajo jugo un papel importante. Astorga, relata esa situación al comentar que:

La vida y la forma de trabajo del peón rural sufrieron un cambio espectacular: habituado a trabajar en sus tierras en actividades agricolas con técnicas tradicionales cerca de sus familias, y a utilizar grandes cantidades de fuerza de trabajo, tuvo que salir hacia regiones lejanas donde surgía una acelerada transformación capitalista. En los años cuarenta, miles de peones salieron prácticamente forzados hacia $\mathrm{Si}$ naloa, Sonora y Mexicali al cultivo del algodón... (Astorga, 1985:74).

Pero no sólo los migrantes internos hacían acto de presencia, sino también los migrantes internacionales. Por esas fechas el programa de braceros implementado entre nuestro país y los EUA movilizo a un gran número de trabajadores hacia la frontera norte. La promesa de conseguir un empleo bien remunerado, la facilidad con la que se podía cruzar la línea divisoria para trabajar en EUA, la posibilidad de obtener papeles para vivir en el país más rico del mundo, atrajo a una gran población "muchos fueron atraídos por la leyenda de la bonanza de Estados Unidos, que alcanzaba a los pobladores fronterizos" (Gómez, 1992:86).

\footnotetext{
${ }^{12}$ Para el ciclo 1955-1956 alcanzó una superficie de 195206 hectíreas sembradas cifra que jamas volvió a presentarse (ver cuadro 1).
} 
Cuadro 1. Serie histórica de la producción de algodón 1912-1994.

\begin{tabular}{|c|c|c|c|}
\hline Ciclo & $\begin{array}{c}\text { Superficie } \\
\text { sembrada ha }\end{array}$ & Ciclo & $\begin{array}{c}\text { Superficie } \\
\text { sembradas ha }\end{array}$ \\
\hline $1912-1913$ & 12 & $1954-1955$ & 193223 \\
\hline $1913-1914$ & 4400 & $1955-1956$ & 195206 \\
\hline $1914-1915$ & 12800 & $1956-1957$ & 165000 \\
\hline $1915-1916$ & 12000 & $1957-1958$ & 184678 \\
\hline $1916-1917$ & 18000 & $1958-1959$ & 191300 \\
\hline $1917-1918$ & 23200 & $1959-1960$ & 142243 \\
\hline $1918-1919$ & 38000 & $1960-1961$ & 138609 \\
\hline $1919-1920$ & 40000 & $1961-1962$ & 135155 \\
\hline $1920-1921$ & 50000 & $1962-1963$ & 131435 \\
\hline $1921-1922$ & 34000 & $1963-1964$ & 129034 \\
\hline $1922-1923$ & 54000 & $1964-1965$ & 133277 \\
\hline $1923-1924$ & 60000 & $1965-1966$ & 128286 \\
\hline $1924-1925$ & 54800 & $1966-1967$ & 134482 \\
\hline $1925-1926$ & 60000 & $1967-1968$ & 128780 \\
\hline $1926-1927$ & 52000 & $1968-1969$ & 82279 \\
\hline $1927-1928$ & 44000 & $1969-1970$ & 75419 \\
\hline $1928-1929$ & 64000 & $1970-1971$ & 57971 \\
\hline $1929-1930$ & 58800 & $1971-1972$ & 57570 \\
\hline $1930-1931$ & 40000 & $1972-1973$ & 49759 \\
\hline $1931-1932$ & 27600 & $1973-1974$ & 41295 \\
\hline $1932-1933$ & 10800 & $1974-1975$ & 91561 \\
\hline $1933-1934$ & 21600 & $1975-1976$ & 42758 \\
\hline $1934-1935$ & 22000 & 1976-1977 & 42439 \\
\hline $1935-1936$ & 45200 & $1977-1978$ & 61508 \\
\hline $1936-1937$ & 55600 & $1978-1979$ & 64083 \\
\hline $1937-1938$ & 55200 & $1979-1980$ & 72286 \\
\hline $1938-1939$ & 37600 & $1980-1981$ & 77492 \\
\hline $1939-1940$ & 40400 & $1981-1982$ & 82229 \\
\hline $1940-1941$ & 48800 & $1982-1983$ & 46217 \\
\hline $1941-1942$ & 71600 & $1983-1984$ & 45955 \\
\hline $1942-1943$ & 82158 & $1984-1985$ & 79776 \\
\hline $1943-1944$ & 89458 & $1985-1986$ & 41018 \\
\hline $1944-1945$ & 87904 & $1986-1987$ & 43913 \\
\hline $1945-1946$ & 64219 & $1987-1988$ & 65974 \\
\hline $1946-1947$ & 68518 & $1988-1989$ & 43034 \\
\hline $1947-1948$ & 67775 & $1989-1990$ & 46162 \\
\hline $1948-1949$ & 78414 & $1990-1991$ & 39305 \\
\hline $1949-1950$ & 105000 & 1991-1992 & 21306 \\
\hline $1950-1951$ & 132800 & $1992-1993$ & 599 \\
\hline $1951-1952$ & 168000 & $1993-1994$ & 12472 \\
\hline $1952-1953$ & 168000 & & \\
\hline $1953-1954$ & 174067 & & \\
\hline
\end{tabular}

FUENTE: Hasta 1957: Asociación Algodonera de Mexicali y San Luis Río Colorado, Son. (1958); 1958-1970: Zamora (1977); 1970-1994: SARH (Varios ańos). 
Comenzaron a llegar a la region trabajadores de Jalisco, Michoacan, Guanajuato, Zacatecas, Guerrero y Oaxaca que ya habfan terminado sus contratos con las empresas extranjeras en los Estados Unidos y en lugar de retornar a sus tierras de origen se quedaban a buscar trabajo en el valle de Mexicali (Sánchez, 1990:51).

Durante la década de 1940-1950, la región experimento los más grandes promedios de inmigración y crecimiento poblacional de toda su historia. En ese periodo las tasas de crecimiento medio anual fueron del 9.4\% (Martínez, 1987:21).

Cuadro 2. Evolución de la migración en el estado de Baja California y municipio de Mexicall (1940-1980).

\begin{tabular}{ccccc}
\hline Afo & \multicolumn{2}{c}{$\begin{array}{c}\text { Estado de B.C. } \\
\text { \% Población } \\
\text { Población } \\
\text { nacida en } \\
\text { B.C. }\end{array}$} & $\begin{array}{c}\text { Municipio de Mexicali } \\
\text { inmigrante } \\
\text { Población } \\
\text { nacida en } \\
\text { Mexicali }\end{array}$ & $\begin{array}{c}\text { Población } \\
\text { inmigrante }\end{array}$ \\
\hline 1940 & 44.1 & 54.9 & 36.8 & 63.2 \\
1950 & 37.0 & 63.0 & 34.5 & 66.5 \\
1960 & 37.8 & 62.2 & 36.6 & 63.4 \\
1970 & 59.7 & 40.3 & 64.5 & 35.5 \\
1980 & 60.0 & 40.0 & 60.8 & 39.2 \\
\hline
\end{tabular}

FUENTE: Los datos de 1940-1950, corresponden a Ladman (1975). Datos de 1960-1980, tomados de los Censos generales de población y vivienda. 1960, 1970, 1980.

El mismo autor lo atribuye al incremento tan extraordinario de la producción algodonera, no sólo del valle de Mexicali, sino de los municipios fronterizos donde el algodon era el cultivo predominante. Pero habría que agregar también, la continuación del programa de "braceros" establecido en 1942.

\section{El mercado de trabajo en el periodo 1937-1967}

Durante todo este periodo que va de 1937 hasta los últimos años de la década de los sesenta, la mano de obra mexicana de origen migrante se constituyo en el pilar de la producción agrícola.

Ante la incapacidad crónica del mercado de trabajo local para abastecer de mano de obra suficiente que levantara las cosechas, los nuevos productores de algodón locales continuaron la política de enganchar trabajadores desde sus lugares de origen, estableciendo una ruta permanente que 
incluyó varios estados del noroeste y el occidente del pais ${ }^{13}$. Además, hicieron llamados a las autoridades para que los braceros que no podfan obtener un contrato y que se encontraban en la ciudad de México, fueran enviados para las cosechas del valle mexicalense.

De esta forma, durante las décadas de los cincuenta y sesenta en cada ciclo algodonero, del total de trabajadores ocupados - aproximadamente 30000 - cuando menos tres cuartas partes eran inmigrantes (Stamatis, 1992b:36). En 1970 la actividad agrícola en el valle daba ocupación a 45000 jornaleros eventuales, de los cuales la mayoría provenfan de otros estados.

Por lo regular, esta mano de obra era joven, fundamentalmente del sexo masculino, con porcentajes importantes de solteros o sin compromisos familiares, por lo que venían solos. Su extracción era fundamentalmente campesina con fuertes nexos con la tierra.

Hasta la segunda mitad de los setenta, el cultivo algodonero continuaba generando el mayor porcentaje del empleo agrícola en el valle; sin embargo, en los años posteriores paulatinamente fue perdiendo ese papel preponderante.

\section{La crisis de la producción agrícola, cambio en el patrón de cultivos}

La politica agricola implementada por los gobiemos poscardenistas, desde los años cuarenta trajo sus consecuencias funestas para el campo mexicano en las décadas posteriores. El desarrollo desigual dentro del sector agrícola, y la transferencia de recursos para un sector urbano e industrial que comenzaba a despegar, erosionó la base económica de la pequeña propiedad. La pérdida de la autosuficiencia alimentaria pronto se hizo evidente.

Al final de los años sesenta, se presenta una crisis mundial en los precios del algodón, provocada fundamentalmente por la entrada de las fibras sintéticas al mercado y la incorporación de otros países a la competencia. Esa situación trajo un descenso en el precio de la fibra, lo cual repercutió hondamente en el valle mexicalense.

En la misma fecha se presentaron otras situaciones negativas para la agricultura local, tales como la incidencia de plagas y el problema de la salinidad de las tierras, que terminó por colapsar la ya de por sf golpeada economía agrícola local.

\footnotetext{
13 Para abundar más sobre las diferentes rutas migratorias, véase Pare (1977). Posadas (1978) y SARH (1990). Es importante resal tar que la corriente migratoria del noroeste actualmente se ha fraccionado en varias vertientes.
} 
La crisis del algodón trajo graves repercusiones para el empleo agricola local, principalmente para la mano de obra migrante que llegaba en todas las temporadas de pizca. Para el ciclo agrícola 1965-1966 la producción de algodón requirió de solo 6255590 jornales, cuando en otros años esas cantidades se duplicaban. Lo anterior reflejo una notable disminución de empleo para la población migrante (Fuentes, 1990:88).

Es difícil cuantificar realmente la cantidad de trabajadores que se quedaron sin laborar durante esos años por la crisis del algodon en el valle de Mexicali. Fuera de los pizcadores, la industria algodonera también generaba empleos en las actividades de procesamiento del producto, en las plantas despepitadoras, en las extractoras de aceites o molinos, desborradoras, fábricas de trapeadores, de colchones, etcétera.

También habría que mencionar los empleados indirectos que laboraban en la infraestructura comercial y servicios financieros que dependian de la fibra del algodón.

Algunos jornaleros agricolas cambiaron sus actividades tradicionales y se dedicaron a laborar en otras más redituables o bien incursionaron en la llamada economía informal.

Ante la crisis que se venía manifestando en la producción del valle de Mexicali, se presentó una diversificación del patrón de cultivos, el algodon perdió su supremacía y otros productos como el trigo, los forrajes y las hortalizas toman un gran auge, dando una nueva fisonomía a la producción. El estado mexicano entra al rescate y brinda apoyo crediticio a los productores que cultivan estos productos.

\section{RECOMPOSICIÓN DEL MERCADO LABORAL: LA SITUACIÓN ACTUAL DE LA MANO DE OBRA EN EL VALLE DE MEXICALI}

Para los ochenta, las hortalizas adquieren tal relevancia nacional que se convirtieron en los productos generadores de $42 \%$ de las exportaciones no petroleras del pars (Stamatis, 1992a:13). A las zonas agricolas de riego tradicionales en el cultivo hortícola, como el valle de Culiacan, se suman los valles de San Quintín y posteriormente el de Mexicali. En este último, representó a fines de la década 34\% de la ocupación agricola (Stamatis, 1992a:64).

Para 1990, las hortalizas contribuyeron con $41 \%$ del valor de las exportaciones agropecuarias (Stamatis, 1992a:10-13).

En los últimos veinte años estos cultivos fueron los que presentaron mayor dinamismo, incrementando su participación en las exportaciones nacionales, de $10 \%$ en 1970 a $36 \%$ en 1990 (Stamatis, 1992a:10-13).

Debido a los cambios operados en la producción agrícola del valle, a la crisis del algodón, al incremento de otros cultivos que no requieren 
mucha mano de obra y principalmente al auge de las hortalizas, se inicio un proceso de reorganización en el mercado de trabajo agrícola local, debido en gran parte a que la población migrante que se fue quedando sin empleo en la cosecha del algodón, comenzó a colocarse en la producción hortícola y a establecerse de forma permanente en la localidad trayendo como resultado el incremento de asentamientos de trabajadores en la zona rural de la region.

Por otro lado, este grupo de cultivos trajo un cambio en la composición de la fuerza de trabajo de la región, ya que en su producción y cosecha se utiliza mano de obra femenina e infantil.

En la actualidad, es común encontrar en las zonas hortícolas del valle de Mexicali, a familias completas durante la cosecha del cebollín, rábano, ajo y melón.

\section{Segmentación del mercado laboral}

Con la diversificación del patrón de cultivos, el crecimiento de la producción de hortalizas y una distribución más homogénea de la demanda de fuerza de trabajo durante el ciclo agrícola, se ha venido modificando la estructura de la ocupacion. Resultado de ello es que, por primera vez en la historia del valle, el trabajador local constituye el tipo predominante en la fuerza de trabajo agrícola (Stamatis, 1992b:46).

Durante los últimos años se ha venido configurando en el valle de Mexicali un mercado laboral diversificado, con cierta especialización en determinados cultivos, pero que en escencia muestra una segmentación entre los jornaleros que ya residen en la localidad y aquellos que vienen de otros estados en forma temporal. Aunque presentan cierta homogeneidad como clase social "hacia afuera" (Stamatis, 1992a:9), muestran una diferenciación interna en sus características socioeconómicas y en sus condiciones laborales; de esta forma, la dimensión principal de la segmentación laboral, recae en la característica de condición migratoria y lugar de residencia.

Así, tenemos que en la actualidad en el sector agricola del valle de Mexicali encontramos un mercado laboral segmentado que da empleo a 25000630000 mil jornaleros, en donde se identifican, por sus características particulares, dos grandes grupos de trabajadores agricolas: el primero, compuesto por jornaleros migrantes provenientes de Sinaloa, Nayarit, Michoacán, Jalisco y Guanajuato, que vienen por temporadas a la raquítica pizca del algodón y los que son originarios pricipalmente de Oaxaca que se ocupan en las cosechas de algunas hortalizas. Estos trabajadores tienen las peores condiciones laborales. 
En el caso de los trabajadores agrícolas migrantes que laboran en el algodón, en su gran mayoría es una mano de obra madura, generalmente varones que vienen solos, con poca relación con la tierra y un nivel muy bajo de escolaridad; en cuanto a los segundos, se tiene que los trabajadores migrantes de las hortalizas, en un porcentaje importante son de origen mixteco, y es una mano de obra bastante joven que viene acompañado de su familia, al igual que otros migrantes, también tienen un bajo nivel escolar, pero un porcentaje importante mantiene relación todavia con la tierra (IIS-PRONSJAG, 1994).

El otro gran grupo lo constituyen los trabajadores locales que residen en el valle, de los que $50 \%$ aproximadamente ya han nacido en la entidad, es decir, son nativos (IIS-PRONSIAG, 1994), mientras que la otra mitad tienen un origen inmigrante. Ellos se ocupan en las cosechas de las hortalizas y presentan mejores condiciones laborales y de vida que sus compañeros migrantes. Son pocos los que todavía mantienen relación con la tierra. Aunque ya tienen su residencia habitual en el valle de Mexicali, en ocasiones se trasladan a otras zonas agrícolas del estado.

\section{ALGUNOS COMENTARIOS FINALES}

Como ya se ha mencionado anteriormente, el valle de Mexicali, historicamente ha sido receptor de fuerza de trabajo migrante. Desde su génesis como zona agrícola, había sido incapaz de satisfacer las necesidades de mano de obra, por lo que se tuvo que recurrir a la contratación de trabajadores foráneos.

Durante las primeras décadas fueron los trabajadores chinos quienes sostuvieron en sus espaldas el peso de las riquezas de la produccion agrícola. Después de la reforma agraria hasta la crisis del algodón en los años sesenta, la mano de obra migrante mexicana asumi 6 el papel preponderante y se convirtió en el pilar de la fuerza de trabajo en la región.

Con la disminución de la superficie sembrada de algodón desde la década de 1970 y la introducción e incremento de cultivos horticolas, se dio un proceso de reorganización del empleo agrícola, algunos trabajadores de la corriente migratoria tradicional (del algodon) se establecieron en los alrededores de los campos hortícolas convirtiéndose en residentes y obligando a sus compañeros locales a entrar en competencia por el empleo; mientras que otros trabajadores migrantes, provenientes de rutas migratorias diferentes a la tradicional, comenzaron a hacer también acto de presencia. Esta situación permitió que en pocos años se consolidara un mercado de trabajo segmentado, compuesto por mano de obra local y otro que incorpora a mano de obra migrante. 
Por primera vez en la historia laboral del valle de Mexicali, se puede hablar de un mercado de trabajo estable y suficiente para cubrir las necesidades que la producción demanda.

\section{BIBLIOGRAFIA}

AGUIRRE Bernal, Celso. 1966. Compendio historico-biografico de Mexicali. Mexicali, B.C. Mexicali, Cuauhtémoc.

- 1983. Compendio histórico-biográfico de Mexicali. Mexicali,B.C., 3a. ed. actualizada.

AMAYA Brondo, Guillermo y Miguel Ramos Galván. 1977. Monografía de un distrito de riego. El Río Colorado y el Distrito de Riego No. 14. Memorándum técnico Núm. 363, México, D.F., SARH, Subsecretaria de Agricultura y Operación. Dirección General de Distritos de Riego. ANGUIANO Téllez, María Eugenia. 1987. "Estructura agraria y migración en el valle de Mexicali". Tijuana, B.C., El Colegio de la Frontera Norte, proyecto de investigación, mimeo .

- 1991. "La formación social del valle de Mexicali a principios de siglo". Ponencia presentada el evento cOLEF-1, celebrado en la ciudad de Tijuana B.C. los días 25, 26, y 27 de octubre de 1991.

ANGUIANO Téllez, Maria Eugenia y José A. Moreno Mena. 1988. Los implementos agrícolas en el valle de Mexicali, durante la primera mitad del siglo XX. El Colegio de la Frontera Norte, mimeo, Mexicali, Baja Califomia.

Asociación Algodonera de Mexicali y San Luis Río Colorado, Son. 1958. "La producción algodonera en el valle de Mexicali y San Luis Río Colorado, Sonora" (mimeo), Mexicali, B.C.

ASTORGA Lira, Enrique. 1985. Mercado de trabajo rural en México. La mercancía humana. Ediciones ERA, (Problemas de México), México, D.F.

AUYÓN Gerardo, Eduardo. 1991. El dragón del desierto: los pioneros chinos en Mexicali. Mexicali, B.C.

DE VIVANCO, Aurelio. 1924. Baja California al día. Lower California up to date. Los Angeles:Wolfore Printing Co., edición bilingue.

DIESBACH Rochefort, Marie Nicole. 1976. El proceso de producción en el valle de Mexicali. ¿Para los intereses socio-económicos de México o para intereses ajenos? Tesis de licenciatura, UABC, Escuela de Ciencias Sociales y Políticas, Mexicali, B.C.

ESTRELLA Andrade, Gabriel. 1981. El proceso de urbanización del valle de Mexicali. Tesis de licenciatura. Escuela de Ciencias Sociales y Políticas, UABC. 
FIGUEROA Ramírez, Leticia. 1992. "La organización de jomaleros agrícolas en el valle de Mexicali, 1920-1990". Estudios Fronterizos, revista del Instituto de Investigaciones Sociales de la UABC, número 27-28 enero-abril, mayo-agosto de 1992, Mexicali, B.C.

FUENTES, César Mario. 1990. Análisis de la evolución del patrón de cultivos en el valle de Mexicali.(1965-1985). Tesis de maestria, El Colegio de la Frontera Norte, Tijuana, B.C.

GARDUÑO, Everardo. 1991. Voces y ecos de un desierto fertil. UABC.

GOMEZ Estrada, José Alfredo. 1983. El proceso de aculturación de los cucapá en B.C., Tesis de licenciatura. Esc. de Ciencias Sociales y Políticas, UABC, Mexicali, B.C.

- 1992. Realidad y ensueños: Historia parcial de Baja California a través de las leyendas., UABC.

GRIJALVA Larrañaga, Edna Aidé. 1983. "La Colorado River Land Company". En Piñera Ramírez, David. (compilador). Panorama Histórico de Baja California. Mexicali, B.C, UABC.

HERRERA Canrillo, Pablo, 1976. Colonización del valle de Mexicali. Mexicali, B.C., UABC.

HUDE-HART, Evelyn. 1986. "The Chinese of Baja California Norte 1910-1934", Proceedings of Pacific Coast Council on Latin American Studios. (V. Twelve, 1985-86), San Diego State University Pres. S.D. $\mathrm{Ca}$.

IIS-PRONSJAG. 1994. "Encuesta a trabajadores agrícolas del valle de Mexicali", proyecto de investigación coordinado por el Instituto de Investigaciones Sociales-UABC con financiamiento del Programa Nacional de Solidaridad con Jomaleros Agrícolas, 1993-1994.

LADMAN, Jerry. 1975. El desarrollo de la economía regional de Mexicali, Un ejemplo de crecimiento impulsado por la exportación. Tempe Arizona, Universidad Estatal de Arizona.

MARTÍNEZ, Carolina y Lerner, Susana, (compiladoras). 1992. Poblamiento, desarrollo agrícola y regional, SOMEDE.

MARTÍNEZ, Sandoval, Rodrigo. 1987. "Los distritos de riego y su impacto en el desarrollo de la frontera norte (apuntes preliminares)". Ponencia presentada en el ler. Encuentro sobre problemas del campo en el noroeste de México y el suroeste de los Estados Unidos. Efectuados en la ciudad de Culiacán, Sinaloa, los días 13 al 16 de enero de 1987.

PARE, Luisa. 1977. El proletariado agrícola en México, Siglo xxI, $6 \mathrm{a}$. ed.

POSADAS Segura, Florencio. 1978. El proletariado agricola en Sinaloa, U.A.S. 
RODRIGUEZ L., Abelardo. 1927. Memoria administrativa del Gobierno del Distrito Norte de la Baja California 1924-1927. Mexicali, Gobiemo del Distrito Norte.

SAMANIEGO López, Marco Antonio. 1991. "Las dificultades económicas y los cambios políticos, 1920-1923", en Martínez Zepeda, Jorge y Romero Navarrete Lourdes (editores), Mexicali. Una historia. UABC.

SÁNCHEZ, Ramírez, Oscar. 1990. Crónica agrícola del valle de Mexicali, UABC, Mexicali, Baja California.

SARH. s/f. "Informes de los ciclos de cultivo" (mimeo), SARH, Delegación Mexicali.

- 1990. Jornaleros Agrícolas en México, Vol. II, México, 1990.

SILVA Herzog, Jésus. 1976. Breve historia de la Revolución Mexicana. México, FCE, tomo I.

STAMATIS Maldonado, Martha. 1987. "El valle de Mexicali: agricultura e inversion extranjera" (1901-1986), Estudios Fronterizos, nS-UABC, año V, vol. V, núms. 12-13, Mexicali, B.C.

- 1992a. "Agroquímicos, salud pública y medio ambiente en la frontera norte: la producción de hortalizas de exportación", proyecto de investigación, ns-UABC, mimeo.

- 1992b. "El impacto de la inversión extranjera en el patrón de cultivos y la fuerza de trabajo agrícola en el valle de Mexicali", en Martínez, Carolina y Lerner, Susana, (compiladoras). 1992. Poblamiento, desarrollo agrícola y regional, SOMEDE.

SOLENO Benavente, Luis. 1972. Estudio general sobre el aprovechamiento de las aguas del Río Colorado en el valle de Mexicali, B.C y San Luis Rfo Colorado, Sonora. Ciudad Juárez Chih., Escuela Superior de Agricultura "Hermanos Escobar" Inc. a la Universidad Autónoma de Chihuahua, Chihuahua.

VALENZUELA, Jose. 1958. "La formación geologica del bajo Río Colorado", en Memoria del Primer Congreso de Historia Regional. Dirección General de Acción Círica y Cultural, Gobiemo del Estado de Baja California, Mexicali, B.C.

ZAMORA, Emilio. 1977. El agua, la tierra. Los hombres de México, $\mathrm{FCE}$, México. 